\title{
Pedir perdón en latín. El acto de habla de la disculpa en las obras de Plauto y Terencio*
}

\author{
Luis Unceta Gómez \\ Universidad Autónoma de Madrid \\ luis.unceta@uam.es \\ Apologizing in Latin. The Speech Act of Apology \\ in Plautus' and Terence's Comedies
}

\begin{abstract}
El presente trabajo propone un análisis pragmático de la noción de «disculpa» en el corte sincrónico que reflejan las obras de Plauto y Terencio, lo que permite profundizar en la expresión de la cortesía lingüística en latín. El acto lingüístico de la disculpa se define como el intento de reparar una ofensa cometida contra el interlocutor, para así regresar a la situación de equilibrio original. Por ello, resulta un acto de habla intrínsecamente cortés hacia el destinatario, pues salvaguarda su imagen social, mientras que pone en peligro la del emisor. Se ofrece aquí una descripción de las estrategias expresivas para la disculpa reconocibles en el corpus mencionado, que atiende a los contextos de uso y a posibles diferencias provocadas por el perfil del hablante.
\end{abstract}

Palabras clave: Plauto; Terencio, Pragmática; Cortesía lingüística; Disculpa.
This paper presents a pragmatic analysis of the notion of «apology» in the synchronic stage reflected in the comedies written by Plautus and Terence. This allows to deepen the understanding of the expression of linguistic politeness in Latin. The linguistic act of apology is defined as the attempt of repairing an offence committed against the addressee, in order to recover the former situation of equilibrium. Thus, apologies are inherently polite speech acts that threaten the speaker's social face, while protecting the addressee's public self image. The study offers an overview of the expressive strategies for apologizing that can be recognized in the abovementioned works, taking into consideration the contexts of use and the differences caused by the speaker's profile.

Key words: Plautus; Terence; Pragmatics; Linguistic politeness; Apology.

* El presente trabajo ha sido realizado en el marco del proyecto de investigación «Semántica latino-románica: unidades de significado procedimental. Diferencias conservadoras e innovadoras del latín al español y afinidades con otras lenguas» (FFI2012-34826), subvencionado por el Ministerio de Economía y Competitividad. Así mismo, se ha beneficiado de una ayuda del programa de movilidad «José Castillejo» del Ministerio de Educación, Cultura y Deporte (CAS12/00065). 


\section{LA CORTESÍA LINGÜÍSTICA Y LA LENGUA LATINA}

La cortesía lingüística, es decir, el análisis de las estrategias comunicativas de las que se sirven los hablantes para evitar el conflicto con su interlocutor cuando los intereses de ambos no son coincidentes, ha suscitado en los últimos años un notorio interés en la descripción de numerosas lenguas, lo que ha permitido hacer considerables avances en este campo de la pragmática. Sin embargo, hasta el momento estos fenómenos no han sido suficientemente examinados en las lenguas clásicas ${ }^{1}$. El presente trabajo pretende ser una contribución en este sentido, a través del análisis de un acto de habla que es deferente con el oyente y, por tanto, resulta intrínsecamente cortés: la disculpa. Para ello, y dadas las limitaciones que impone la falta de plena competencia sobre las lenguas antiguas — más notoria aun en el nivel de análisis pragmático- y la naturaleza exclusivamente escrita de la documentación disponible, el modelo teórico clásico de cortesía lingüística propuesto por Brown y Levinson 1987, pese a las críticas de que ha sido objeto ${ }^{2}$, proporciona en sus líneas maestras un marco metodológico suficientemente explicativo ${ }^{3}$. Heredera de las máximas conversacionales de Grice, la propuesta de estos autores se articula en torno al concepto de «imagen» (face), la proyección pública que posee todo individuo, definida del siguiente modo:

Face is something that is emotionally invested, and that can be lost, maintained, or enhanced, and must be constantly attended to in interaction. In general, people cooperate ... in maintaining face in interaction, such cooperation being based on the mutual vulnerability of face (Brown y Levinson 1987, p. 61).

${ }^{1}$ Existen, con todo, algunos trabajos que abordan aspectos parciales de la cortesía en latín; sin afán de exhaustividad, pueden mencionarse Roesch 2004, Unceta Gómez 2009, 2010, Ferri 2008, 2012, Brookins 2010, Dickey 2012, o la monografía de Hall 2009. Para una visión de conjunto, véase Unceta Gómez 2014. Kruschwitz y Cleary-Venables 2013 (trabajo del que hemos tenido conocimiento solo tras finalizar el nuestro) analiza las disculpas en la obra de Terencio partiendo de una clasificación diferente a la que aquí se propone y de una definición de disculpa más amplia que la que manejamos.

${ }^{2}$ Las críticas apuntan especialmente a sus pretensiones de universalidad, la preeminencia que otorga a la cortesía negativa o el hecho de considerar amenazante cualquier acto comunicativo.

${ }^{3}$ Las nuevas aproximaciones a los fenómenos de cortesía, como Watts 2003, que pretenden ahondar en la interpretación del acto discursivo por parte del interlocutor y en la construcción dinámica de la cortesía en el discurso (modelos llamados de «cortesía de primer orden»), resultan difícilmente aplicables a una lengua como el latín — para la que contamos con muy pocos juicios de aceptabilidad pragmática-, debido a su nula capacidad predictiva (cf. Dickey 2012). 
Dicho concepto comprende dos facetas complementarias: la imagen positiva, que se define como la aspiración de reconocimiento o aprobación social, y la imagen negativa, que implica el deseo de desarrollar sin impedimentos las aspiraciones propias. Para evitar el enfrentamiento que podría derivarse de deseos encontrados, los hablantes han de servirse de ciertas estrategias expresivas que mitiguen la amenaza que algunos actos comunicativos implican para la imagen del interlocutor y permitan salvaguardar la propia. De la gravedad de esa amenaza, por último, dan cuenta parámetros como la distancia social entre los participantes en el acto comunicativo - que incide en la formalidad de la situación-, su jerarquía relativa y la valoración que cada cultura concede a un acto de habla determinado.

\section{El aCto DE habla de LA Disculpa}

Desde un punto de vista pragmático, la disculpa es una intención comunicativa que, junto con la felicitación, el agradecimiento, la condolencia o el halago, es clasificada por Searle 1976 entre los «actos de habla expresivos», definidos por este autor como aquellos actos ilocutivos ${ }^{4}$ que expresan una emoción e implican la verdad de la proposición que describe la situación responsable de esa emoción ${ }^{5}$. Por medio de una disculpa, el hablante reconoce la comisión de una falta o la violación de una norma social que afecta negativamente al receptor del mensaje. En su manifestación prototípica, el emisor se identifica habitualmente con el agente de la ofensa, si bien cabe la posibilidad de que un tercero interceda ante alguien para tratar de conseguir el perdón de una falta ajena ${ }^{6}$. El objetivo del emisor es la recuperación del equilibrio preexistente a la transgresión, de manera que su enunciación

${ }^{4}$ El acto ilocutivo es la parte intencional del acto de habla, la finalidad comunicativa concreta que el hablante persigue con su emisión lingüística.

${ }^{5}$ Cf. Norrick 1978. Cabe señalar, con todo, que este tipo de enunciados suelen estar fuertemente convencionalizados y su empleo se relaciona en muchas ocasiones con imposiciones y expectativas sociales, lo que vuelve irrelevante la sinceridad de las emociones que expresan.

${ }^{6}$ Aunque en la bibliografía no suelen tratarse de manera conjunta, en el presente trabajo contemplamos los actos de intercesión, es decir, la solicitud de disculpas en beneficio de otro, por entender que la principal diferencia radica en el beneficiario del acto perlocutivo (es decir, de los resultados que pueda suscitar), que no coincide con el emisor del mensaje. Como veremos, las estrategias expresivas, salvo ligeras desviaciones, coinciden, por lo que esta inclusión no distorsiona la taxonomía propuesta. 
suele ser posterior a la falta, aunque en algunas culturas no es infrecuente su empleo previo a la infracción. En cualquier caso, se trata de una acción lingüística que pretende ser compensatoria.

Con su realización, el emisor suele reconocer, al menos parcialmente, su culpabilidad, con lo que refuerza la imagen social del destinatario, mientras que amenaza la propia y merma su poder simbólico ${ }^{7}$. Ello convierte la disculpa en un acto marcadamente cortés en el que, al igual que los agradecimientos $^{8}$, los buenos deseos, los cumplidos o las felicitaciones, el objetivo ilocutivo refuerza la dimensión social por resultar deferente con el oyente (cf. Kasper 1990, pp. 197-198).

La disculpa es, junto con la petición, uno de los actos de habla que más bibliografía ha generado ${ }^{9}$, tal vez, como señala Meier 1998, p. 227, por el hecho de que, dada su función reparadora de un comportamiento que se desvía de la norma, proporciona un objeto de estudio idóneo para captar la relación entre parámetros culturales y comportamiento lingüístico. Precisamente por ello, es indispensable tomar ciertas precauciones a la hora de abordar su análisis en las sociedades antiguas.

${ }^{7}$ Cf. Blum-Kulka y Olshtain 1984, p. 206. De acuerdo con Brown y Levinson 1987, la disculpa, como estrategia de cortesía negativa que implica respeto y deferencia hacia el interlocutor, resulta amenazadora para la imagen positiva del emisor. Ogiermann 2009, sin embargo, defiende la postura contraria y ve en la disculpa una muestra de cortesía positiva, puesto que su objetivo prioritario es el de restaurar y mantener relaciones sociales. El riesgo para la imagen positiva del emisor reside, precisamente, en no solicitar perdón tras la comisión de una falta (cf. pp. 52, 260). Así lo defiende también Horacio (Sat. I 3), quien recomienda perdonar a los amigos y relativizar sus faltas como el mejor modo para mantener los lazos de amistad; véase al respecto Schrijvers 1993, p. 76, donde se aplica la teoría de Brown y Levinson a la obra del poeta.

${ }^{8}$ Sobre las similitudes tipológicas entre la expresión de gratitud y la de disculpa, cf. Coulmas 1981. Acerca de la expresión del agradecimiento en el latín de las comedias, puede verse Unceta Gómez 2010.

9 Por citar solo algunas referencias, la visión de conjunto de Lakoff 2001 y el estado de la cuestión de Meier 1998, centrado en el inglés, son buenos acercamientos al tema; cabe destacar por su influencia Fraser 1981, Olshtain y Cohen 1983, Blum-Kulka y Olshtain 1984, Olshtain 1989. El trabajo de Ogiermann 2009 recoge buena parte de la bibliografía publicada hasta la fecha y ofrece un análisis intercultural del fenómeno basado en la teoría clásica de Brown y Levinson. Hatfield y Hahn 2011 presentan un análisis de las disculpas en coreano que combina este modelo con las nuevas teorías sobre cortesía lingüística. Entre los estudios contrastivos pueden mencionarse además Márquez Reiter 2000, Siebold 2007, Bataineh y Bataineh 2008. 
Si atendemos a la tesis de Konstan, no es posible hablar de «perdón» ${ }^{10}$ en la Antigüedad grecorromana, puesto que no se constatan algunos procesos emocionales como el remordimiento, el arrepentimiento o el cambio de actitud que deriva de ellos ${ }^{11}$. De tal modo, las intervenciones tradicionalmente interpretadas como disculpas habrían de entenderse mejor como intentos convencionales de aplacar la cólera del destinatario; una declaración de culpabilidad de un esclavo, por ejemplo, constituye un acto que no pretende alterar la relación con el amo, sino que se limita a enfatizar la superioridad de este último (Konstan 2012, p. 20) ${ }^{12}$.

Es esta una situación que podemos documentar en la sociedad romana, donde cabe la posibilidad de proporcionar reparación a una afrenta sin que medie la verbalización de una disculpa, algo que permite recuperar el equilibrio sin dar muestras de debilidad. Precisamente esa es, en el ejemplo (1), la intención del

${ }^{10}$ Definido por Konstan 2011, p. 21, en los siguientes términos: «a bilateral process involving a confession of wrongdoing, evidence of sincere repentance, and a change of heart or moral perspective ... on the part of the offender, together with a comparable alteration in the forgiver, by which she or he consents to forego vengeance on the basis precisely of the change in the offender». Este autor sitúa el origen del concepto moderno de perdón en el siglo XVII.

${ }^{11}$ Konstan hace referencia a la frecuencia en la literatura grecolatina de las excusas destinadas a obviar la responsabilidad de los actos cometidos, lo que demostraría la inexistencia del sentimiento de arrepentimiento. No es este el lugar para discutir esta idea, pero algunos pasajes cómicos, especialmente en las obras de Terencio, documentan claramente remordimientos o arrepentimiento. Véase, por ejemplo, la larga tirada de Ter., Haut. 121-150, donde un padre, atormentado por haber empujado a su hijo al ejército como mercenario, se autoimpone el castigo de llevar la vida de un granjero. Las obras de Plauto proporcionan también ejemplos, como Capt. 993-996. Fulkerson 2013, quien ofrece una útil visión de conjunto sobre el fenómeno (véase especialmente el capítulo V, «Comedy means (almost) never having to say you're sorry», pp. 114-132), señala (p. 116) que el hecho de que la comedia no sea un género moralizante explica que en estas obras no se explore la sinceridad del arrepentimiento (más clara en Terencio que en Plauto), pero no impide su manifestación.

12 Según la descripción de Gutzwiller 2012, pp. 49-50, además, en las relaciones de la élite aristocrática arcaica, como las que representan, por ejemplo, los poemas homéricos, admitir un error y pedir perdón conllevan la asunción de una posición jerárquica subordinada; del mismo modo, dispensar un perdón gratuito, renunciando a la venganza o a una contraprestación, se considera una muestra de debilidad. Sobre las disculpas en la épica homérica, véase además Scodel 2008, pp. 95-125, para quien, aunque no puedan ser plenamente equiparados con las disculpas en sentido moderno, los héroes se implican en actos de reparación. Sobre las excusas como forma de eludir una disculpa en Homero, cf. Taffeteller 2003. 
senex Perífanes hacia su esclavo Epídico en la primera parte de su intervención (a través de un acto comisivo en el que se ofrece una reparación; cf. § V.3), aunque finalmente deba plegarse a las exigencias de su siervo - repárese en el uso alternativo del verbo orare, que hace patente que el amo asume una posición subordinada respecto al esclavo- y verbalizar una disculpa:

(1) Ep. Numquam hercle hodie, nisi supplicium mihi das, me solui sinam. / PE. Optumum atque aequissumum oras. Soccos, tunicam, pallium / tibi dabo. Ep. Quid deinde porro? Pe. Libertatem. Ep. At postea? / Nouo liberto opus est quod pappet. PE. Dabitur, praebebo cibum. Ep. Numquam hercle hodie, nisi me orassis, solues. PE. Oro te, Epidice, / mihi ut ignoscas siquid inprudens culpa peccaui mea. / At ob eam rem liber esto. Ep. Inuitus do hanc ueniam tibi, / nisi necessitate cogar. Solue sane si lubet (Plaut., Epid. 724-731) ${ }^{13}$.

Así pues, tal y como trataremos de mostrar en este trabajo, aunque no sea conveniente establecer una equivalencia completa entre los conceptos antiguo y moderno de «perdón», la comedia romana presenta un buen número de situaciones en las que se reconocen solicitudes de disculpa e indulgencia, por lo que no parece recomendable llegar al extremo de negar la existencia del perdón en la Antigüedad ${ }^{14}$. Aun así, resultan innegables las interferencias con la jerarquía relativa entre los interlocutores: si se realiza en sentido ascendente, es decir, se dirige de un inferior a un superior, el estado de subordinación del emisor se intensifica y, como resultado, la superioridad del receptor queda reforzada ${ }^{15}$. En una sociedad en la que el paterfamilias tenía pleno derecho sobre toda su familia, no debe sorprender que el tipo de perdón que interesa sea el que refuerza esa autoridad absoluta (cf. Morton Braund 2012, p. 96). Este factor da cuenta además del carácter humilde y suplicatorio que con

13 Salvo indicación contraria, los textos se citan por las ediciones oxonienses de Lyndsay (Plauto) y Kauer y Lyndsay (Terencio).

${ }^{14}$ En general, las propuestas recogidas en el volumen colectivo editado por Griswold y Konstan 2012 no son tan restrictivas como la interpretación del propio Konstan.

${ }^{15}$ En muchas lenguas modernas, una disculpa en el sentido contrario suele implicar cierta familiaridad entre los interlocutores (Obeng 1999, p. 730). En las comedias cabe pensar en otros factores. El servicio de los esclavos en beneficio de los intereses personales de sus amos debe implicar la clemencia de estos últimos: Ego, Pamphile, hoc tibi pro seruitio debeo, I conari manibu' pedibu' noctesque et dies, / capitis periclum adire, dum prosim tibi; / tuomst, siquid praeter spem euenit, mi ignoscere (Ter., And. 675-678). 
frecuencia asumen las disculpas en la comedia ${ }^{16}$, es decir, resulta indicativo de que el hablante adopta una posición de inferioridad ante su interlocutor. Además del uso de determinados verbos realizativos (infra, § IV) ${ }^{17}$, la valoración que se hace de estos actos no deja lugar a dudas:

(2) Сн. Vt qui deliquit supplex est ultro omnibus! (Plaut., Bacch. 1024).

(3) [Рн.] uenias nunc precibu' lautum peccatum tuom? (Ter., Phorm. 973).

Por otra parte, a diferencia de las expectativas que crean los parámetros culturales actuales, según los cuales las respuestas —o pares de adyacencia, de acuerdo con la terminología del análisis conversacional— preferentes para una disculpa son bien la minimización (4), bien la concesión del perdón (5) (cf. Fraser 1981, p. 265), o incluso la combinación de ambas (6):

(4) nam nisi qui ipse amauit aegre amantis ingenium inspicit (Plaut., Mil. $638)^{18}$.

(5) Ac. Primum cauisse oportuit ne diceres, / uerum eadem si idem purgas mi, patiunda sunt (Plaut., Amph. 944-945).

(6) ... Тн. Scio, / et pol propterea mage nunc ignosco tibi. / Non adeo inhumano ingenio sum, Chaerea, / neque ita inperita ut quid amor ualeat nesciam (Ter., Eun. 878-881),

en el corpus analizado no es extraño que una disculpa sea rechazada ${ }^{19}$, pues se considera que, en ocasiones, esta no proporciona reparación a la ofensa ${ }^{20}$ :

${ }^{16}$ El hecho de que la disculpa tenga como uno de sus objetivos habituales evitar el castigo físico explica que algunas súplicas expresivas sin contenido proposicional se encuentren en un terreno fronterizo con la disculpa. Así funcionan enunciados como tuam fidem opsecro! (Plaut., Amph. 373); iam opsecro, uxor (Plaut., Asin. 411, 926); obsecro (Ter., Eun. 669); opsecro hercle, Periplectomene, te (Plaut., Mil. 1396).

${ }^{17}$ Los verbos realizativos son aquellos que explicitan léxicamente un acto de habla concreto. Para que sea posible su lectura realizativa, han de enunciarse en primera persona del presente de indicativo. Los verbos realizativos empleados en las disculpas pertenecen a la dimensión rogativa del campo léxico de la petición, según la propuesta de Unceta Gómez 2009, pp. 146-148.

18 Véase infra ej. (22) la disculpa que recibe esta respuesta.

${ }_{19}$ Compárese además con Purgem me? Laterem lauem (Ter., Phorm. 186) y véase infra (15).

${ }^{20}$ Cf. nam qui post factam iniuriam se expurget parum mi prosit (Ter., Hec. 742 ). 
(7) [SA.] tu quod te posteriu' purges hanc iniuriam mi nolle / factam esse, hui(u)s non faciam. Crede hoc, ego meum ius persequar / neque tu uerbis solues umquam quod mihi re male feceris. / Noui ego uostra haec ${ }^{21}$ : «Nollem factum»; iusiurandum dabitur te esse / indignum iniuria hac, indignis quom egomet sim acceptus modis (Ter., $A d$. 162-166).

Una última evidencia del diferente funcionamiento de esta intención comunicativa en el latín de este corte sincrónico con respecto a las lenguas europeas modernas es su escasa automatización en funciones como la solicitud de permiso para una intrusión (perdón, disculpe, de donde su uso como captador de atención; Coulmas 1981, p. 76), su empleo como respuesta negativa a una petición (cf. Edmonson 1981, p. 283), o como movimiento precautorio de un acto de habla que puede no ser bienvenido ${ }^{22}$, si bien algunos indicios permiten postular que estos usos comienzan a convencionalizarse en época de Cicerón ${ }^{23}$. Cabe destacar, por último, el hecho de que en el latín de Plauto y Terencio no se hayan gramaticalizado expresiones de disculpa — piénsese en esp. lo siento, it. mi dispiace, fr. desolé, ing. sorry (cf. Molina Ávila 2011), etc._- a diferencia de lo que ocurre, por ejemplo, con los indicadores de fuerza ilocutiva directiva (amabo, quaeso, obsecro).

\section{Las eXPresiones de disculpa en el latín de Plauto y Terencio}

Si bien la comedia no constituye un corpus plenamente representativo de los usos lingüísticos del hablante latino (está limitado cronológicamente, no se trata de proferencias naturales y la versificación impone restricciones), junto a su naturaleza dialógica, proporciona la innegable ventaja de

${ }^{21}$ Seguimos la puntuación propuesta por Rosivach 1972 para estos versos.

${ }^{22}$ Llamado disarming move por Edmonson 1981, pp. 281-282; véase también Brown y Levinson 1987, p. 189. La disculpa (expresada por carta) reproducida en (17) constituye un paso previo a la solicitud que sigue: «Nunc si me fas est opsecrare aps te, pater, / da mihi ducentos nummos Philippos, te opsecro» (1025-1026), si bien en este caso da respuesta a un agravio real y, por tanto, no debe considerarse necesariamente un movimiento preparatorio con mero carácter cortés. Sobre su uso en Cicerón, cf. Roesch 2004, pp. 150-151.

${ }^{23}$ Cf. Hall 2009, pp. 108, 112-114, y las referencias en p. 232, n. 4, para quien ejemplos como ignosce mihi quod, ..., eadem de re saepius scribam (Cic., Att. XVI 16E.1) son indicativos del uso precautorio. Otras soluciones menos formales (ibíd. p. 233, n. 18) son te deprecor ne ... condemnes (Fam. VII 1.1) o pace tua dixerim (Att. V 17.6). Sen., Benef. V 22 proporciona un ejemplo de disculpa como negativa a una solicitud (Ferri 2012, p. 124). 
que presenta situaciones que muchas sociedades consideran privadas y, por tanto, sus argumentos nos permiten acceder a las ofensas cometidas en el seno de la familia o entre amantes, así como a las estrategias usadas para su reparación ${ }^{24}$.

Como ocurre en muchas otras lenguas, el latín cuenta con diferentes mecanismos para expresar la disculpa, que pueden agruparse en dos grandes bloques en función de si esta se manifiesta de manera explícita o implícita ${ }^{25}$, si bien, como veremos, las estrategias suelen aparecer combinadas de modos distintos. En la formulación de su enunciado, además del mayor o menor grado de responsabilidad asumida en función de la estrategia expresiva elegida, el emisor tiene a su disposición un repertorio de mecanismos atenuantes (downgrading), como el uso de la oración condicional - muy frecuente en la comedia - y la minimización de los efectos de la ofensa, o intensificadores (upgrading), entre los que se reconocen elementos como los adverbios, la duplicación de la disculpa, la combinación de distintas estrategias, elementos expresivos como interjecciones o juramentos, el interés por el oyente, o tratamientos deferentes y elogiosos, que, en (8), contrastan con la autodenigración:

(8) ... So. $M i$ Chreme, peccaui, fateor: uincor. Nunc hoc te obsecro, / quanto tuos est animu' natu grauior, ignoscentior, / ut meae stultitiae in iustitia tua sit aliquid praesidi (Ter., Haut. 644-646).

\section{DisculPas EXPLÍ́citas}

Las expresiones que indican explícitamente su fuerza ilocutiva mediante procedimientos léxicos ${ }^{26}$ suelen estar altamente convencionalizadas e implicar verbos que significan 'perdonar', 'disculpar', 'sentir', etc. En el caso del latín de las comedias, la estrategia más representada consiste en expresiones

${ }^{24}$ Cf. Hatfield y Hahn 2011, p. 1305; solo algunos documentos privados, como las cartas, comparten este valor. Sobre la idoneidad del teatro como corpus para el análisis conversacional, véase además Sánchez Jiménez 2006.

${ }^{25}$ Las clasificaciones de este acto de habla varían de un autor a otro; se toma aquí como base la propuesta de Olshtain y Cohen 1983 — seguida en trabajos recientes como Afghari 2007-, aunque con ciertas modificaciones, para dar cuenta de los datos del latín.

${ }^{26}$ En la bibliografía suelen recibir el nombre de illocutionary force indicating device (IFID). 
realizativas en las que interviene el verbo ignoscere, bien en imperativo, bien como régimen de un verbo de petición:

(9) Iv. Per dexteram tuam te, Alcumena, oro, opsecro, / da mihi hanc ueniam, ignosce, irata ne sies (Plaut., Amph. 923-924).

(10) ... Anta. Ego, Poene, tibi me purgatum uolo. / $\mathrm{Si}^{27}$ quid dixi iratus aduorsum animi tui sententiam, / id uti ignoscas quaeso; et quom istas inuenisti filias, / ita me di ament, mihi uoluptatist. Ha. Ignosco et credo tibi (Plaut., Poen. 1410-1413).

Solo en el caso de las intercesiones, se documentan formas directivas más impositivas, lo que se justifica en el hecho de que el beneficiario del resultado sea distinto del emisor de la solicitud ${ }^{28}$ :

(11) ... CL. Pater, hoc nunc restat. CH. Quid? CL. Syro ignoscas uolo / quae mea causa fecit. CH. Fiat. ... (Ter., Haut. 1066-1067) ${ }^{29}$.

Con una frecuencia muy inferior (algo que invita a pensar en un menor grado de convencionalización), se documentan las expresiones ueniam da, gratiam fac $^{30}$, (noxiam) re-/a-mitte:

${ }^{27}$ Como se ha mencionado, el uso de una oración condicional, frecuente en estas obras, es un procedimiento de minimización de la responsabilidad, por implicar desconocimiento y cuestionar indirectamente la existencia de la ofensa. En el discurso político actual, constituye una de las estrategias más habituales para la salvaguarda de la imagen (cf. Kampf 2009, p. 2267).

${ }^{28}$ En otras dos intercesiones, se documentan además giros directivos negativos con perdere: Per deos atque homines ego te optestor, Hegio, / ne tu istunc hominem perduis (Plaut., Capt. 727-728); Frater, opsecro te, noli hunc condemnatum perdere (Plaut., Curc. 697-698).

${ }^{29}$ Compárese con las disculpas que Clitofón expresa por sus propios actos unos versos antes: Pater, obsecro ignoscas (Ter., Haut. 1049); Si me uiuom uis, pater, / ignosce (ibíd. 1051-1052).

${ }^{30}$ Según señala Moussy 2011, p. 43, uenia posee un significado más cercano al de 'favor' en expresiones directivas como ueniam peto o da ueniam. Como resultado de una solicitud, las fronteras con el concepto de «perdón» son difusas: hanc ueniam illis sine te exorem (Plaut., Bacch. 1199). El significado originario de gratia es también el de 'favor' (ibíd. p. 45). Sobre el léxico del «perdón» en el género historiográfico, v. Newbold 2001a, $2001 \mathrm{~b}$. 
(12) Me. Da ueniam, Chreme: / sine te exorem. ... (Ter., Haut. 1049-1050) ${ }^{31}$.

(13) ... CA. Fac istam cunctam gratiam: / Tranio remitte quaeso hanc noxiam $^{32}$ caussa mea (Plaut., Most. 1168-1169).

(14) ... TH. Credin te inpune habiturum? $\mathrm{CH}_{\mathrm{H}}$. Vnam hanc noxiam / amitte ${ }^{33}$ : si aliam admisero umquam, occidito (Ter., Eun. 852-853).

\section{Disculpas implícitas}

Junto a estos procedimientos, una disculpa puede realizarse por medio de otras estrategias implícitas, consistentes en enunciados que hacen referencia a las condiciones previas o a las consecuencias de la transgresión. Dentro de este grupo se reconocen en las comedias varias categorías, que aquí se presentan ordenadas de mayor a menor grado de implicación en la infracción.

\section{Declaración de responsabilidad}

El reconocimiento de la culpa constituye la máxima implicación con la ofensa cometida y puede servir para tratar de recobrar el equilibrio anterior ${ }^{34}$. En culturas en las que la concesión del perdón resulta una obligación social, se constata una relación directamente proporcional entre el grado de reconocimiento de la culpa y la obtención del perdón. Los escasos ejemplos latinos apuntan también en este sentido, si bien los datos están condicionados por la trama de estas obras. Tras un intento fallido de explicación de las causas, el joven Diniarco confiesa su falta del siguiente modo:

31 Cf. además (24), único ejemplo que no constituye una intercesión. El verbo exorare aparece en otras intercesiones: age iam, sine ted exorarier (Plaut., Most. 1175); sine te exorem (ibíd. 1180).

32 El sustantivo noxia ('delito', 'ofensa') aparece con el verbo sobreentendido en una intercesión: Hanc modo unam noxiam, unam-quaeso, fac caussa mea (Plaut., Most. 1177).

33 Véase también: Ad precatorem adeam credo qui mihi / sic oret: "Nunc amitte quaeso hunc; ceterum / posthac si quicquam, nil precor» (Ter., Phorm. 140-142). También la base se documenta en una intercesión: mitte quaeso istum (Plaut., Most. 1172):

34 A pesar de no estar presente el agraviado - y no poder considerarse, por tanto, un acto realizativo - , encontramos una declaración de culpabilidad (la del padre que se atormenta por el comportamiento que dispensó a su hijo) en: Ita res est, fateor: peccatum a me maxumest (Ter., Haut. 158). 
(15) ... Di. Adsum, Callicles. Per te opsecro / genua ut tu istuc insipienter factum sapienter feras / mihique ignoscas quod animi inpos uini uitio fecerim. / CA. Non placet: ... / Non uinum 〈uiris〉 moderari, sed uiri uino solent, ... / Di. Scio equidem quae nolo multa mi audienda ob noxiam. / Ego tibi me obnoxium esse fateor culpae compotem (Plaut., Truc. 826$829,831,834-835)$.

El mismo procedimiento se reconoce en la súplica intensiva del lenón en el segundo final de Poenulus, en el que Lupo reconoce su delito de proxenetismo, aunque seguidamente intente minimizar el impacto de sus intenciones ${ }^{35}$ :

(16) Ly. Accedam. Per ego te tua te genua opsecro / et hunc, cognatum quem tuom esse intellego: / quando boni estis, ut bonos facere addecet / †facite et $\dagger$ uostro subueniatis supplici. / Iam pridem equidem istas esse sciui liberas / et exspectabam si qui eas adsereret manu. / Nam meae 〈eae〉 prosum non sunt. Tum autem aurum tuom / reddam quod apud me est et iusiurandum dabo / me malitiose nihil fecisse, Agorastocles (Plaut., Poen. 1387-1395).

La confesión de la responsabilidad favorece además las expresiones de autodenigración ${ }^{36}$, que insisten en la culpabilidad:

(17) Ni. «Stulte fecisse fateor. Sed quaeso, pater, / ne me, in stultitia si deliqui, deseras. / Ego animo cupido atque oculis indomitis fui; / persuasumst facere quoius me nunc facti pudet» (Plaut., Bacch. 1013-1016).

(18) ... Sc. Periplectomene, te opsecro / per deos atque homines perque stultitiam meam / perque tua genua-PE. Quid opsecras me? Sc. Inscitiae $^{37}$ / meae et stultitiae ignoscas. Nunc demum scio / me fuisse excordem, caecum, incogitabilem. / Nam Philocomasium eccam intus. ... (Plaut., Mil. 540-545).

En ocasiones, el reconocimiento de responsabilidad sobre la ofensa puede ir acompañado por la minimización de la valoración negativa de la misma, lo

${ }^{35}$ La combinación de estrategias refuerza la intensidad de la disculpa (cf. infra, § VI); pero, al mismo tiempo, como vemos aquí, permite mitigar la amenaza de la imagen que para el emisor implica el núcleo de la disculpa (cf. Obeng 1999, p. 717).

${ }^{36}$ Recuérdese (8) y véanse además las duras palabras con las que Sóstrata se refiere a sí misma en Ter., Haut. 649-651.

${ }^{37}$ Cf. Si peccaui, mi Chreme, / insciens feci (Ter., Haut. 631-632). 
que se interpreta como una justificación (Meier 1998, p. 217). En el transcurso de una plegaria a Venus, la esclava Ampelisca, víctima de un naufragio, trata de que su aspecto indigno para realizar una ofrenda no sea tenido en cuenta $^{38}$ :

(19) PA. ... lautae ambae sumus opera Neptuni noctu, / ne indignum id habeas neue idcirco nobis uitio uortas, / si quippiamst minu' quod bene esse lautum tu arbitrare (Plaut., Rud. 699-701).

El procedimiento se documenta igualmente en el caso de la intercesión:

(20) ... TR. Ausculta modo. / Fateor peccauisse, amicam liberasse apsente te, / faenori argentum sumpsisse; id esse apsumptum praedico. / Numquid aliud fecit nisi quod [faciunt] summis gnati generibus? (Plaut., Most. 1138-1141).

Por último, la expresión de vergüenza ${ }^{39}$ y arrepentimiento, que implican empatía con el receptor ${ }^{40}$, han de considerarse también un reconocimiento implícito de la responsabilidad en el agravio, que puede hacerse explícito, como en (23):

(21) AE. Ita uelim me promerentem ames dum uiuas, mi pater, / ut me hoc delictum admisisse in me, id mihi uehementer dolet / et me tui pudet.... (Ter., Ad. 681-683).

${ }^{38}$ Un ejemplo adicional de justificación podría considerarse: Redeo inde iratus atque aegre ferens; / nec satis ad obiurgandum causae. Diceret / "Quid feci? Quid commerui aut peccaui, pater? / Quae sese in ignem inicere uoluit, prohibui / seruaui.» Honesta oratiost (Ter., And. 137-141). A pesar de que el viejo Simón es consciente de los amoríos de su hijo con una cortesana, no tiene pruebas suficientes y no puede reprochárselo, incluso si llegan a hacerse alguna muestra de cariño en público.

${ }^{39}$ El procedimiento es explotado cómicamente en boca del esclavo Tranión, quien, aprovechando el perdón que el viejo Teoprópides ha dispensado a su hijo Filólaques, pretende obtenerlo también, aludiendo a la última afirmación de Calidámates (dispudet: Plaut., Most. 1166), el joven amigo de Filólaques que ha intercedido por él ante el padre de este último: TR. 〈Post istam ueniam quid me fiet nunciam? / TH. Verberibus, lutum, caedere pendens. TR. Tamen etsi pudet? (ibíd. 1166-1167).

${ }^{40}$ Como expresan ing. I'm sorry, al. tut mir leid, fr. je suis desolé, en la frontera con la expresión de simpatía (Coulmas 1981, p. 76). Kruschwitz y Cleary-Venables 2013, pp. 77-78, hablan de mortification y analizan el ejemplo que reproducimos aquí como (21). 
(22) ... PL. At hoc me facinus miserum macerat / meumque cor corpusque cruciat. Pe. Quid id est quod cruciat? Cedo. / PL. Me tibi istuc aetatis homini facinora puerilia / obicere neque te decora neque tuis uirtutibus; / ea te expetere ex opibus summis mei honoris gratia / mihique amanti ire opitulatum atque ea te facere facinora / quae istaec aetas fugere facta magi' quam sectari solet: / eam pudet me tibi in senecta obicere sollicitudinem (Plaut., Mil. 616-623).

(23) Ni. «Pudet prodire me ad te in conspectum, pater: / tantum flagitium te scire audiui meum, / quod cum peregrini cubui uxore militis» (Plaut., Bacch. 1007-1009).

\section{Promesa de mejora}

La promesa de mejora, frecuente en algunas lenguas modernas europeas, es una estrategia escasamente representada en la comedia, aunque podemos reconocerla, implícitamente al menos, en el desenlace de Casina, donde, tras haber sido descubierto su adulterio, Lisidamo entiende que debe disculparse con su esposa. Ante los reproches de esta y tras un intento de negar la evidencia, la disculpa se articula en los siguientes términos, materializándose en la dilación del castigo a la siguiente ocasión en que se incurra en la falta:

(24) Ly. ... Feci ego istaec dicta quae uos dicitis? / CL. Rogitas etiam? Ly. Si quidem hercle feci, feci nequiter. / CL. Redi modo huc intro: monebo, si qui meministi minus. / Ly. Hercle, opinor, potius uobis credam quod uos dicitis. / Sed uxor, da uiro hanc ueniam «mi〉; Myrrhina, ora Cleustratam; / si umquam posthac aut amasso Casinam aut occepso modo, I ne ut eam amasso, si ego umquam adeo posthac tale admisero, / nulla caussast quin pendentem me, uxor, uirgis uerberes. / My. Censeo ecastor ueniam hanc dandam, 〈Cleustrata〉. CL. Faciam ut iubes. / Propter eam rem hanc tibi nunc ueniam minu' grauate prospero, / hanc ex longa longiorem ne faciamus fabulam. / Ly. Non irata's? CL. Non sum irata. Ly. Tuaen fide credo? CL. Meae. / Ly. Lepidiorem uxorem nemo quisquam quam ego habeo hanc habet ${ }^{41}$ (Plaut., Cas. 996-1008).

${ }^{41}$ La concesión del perdón provoca aquí el agradecimiento en forma de halago (cf. Unceta Gómez 2010, p. 632) y en forma de bendición en (25) (ibíd. 631). Puesto que la promesa de mejora es una de las formas más marcadas como cortesía positiva de todo el repertorio, la escasez de testimonios favorece la idea de que la romana es una sociedad de cortesía negativa. 
El siguiente ejemplo muestra una estructura paralela:

(25) Sc. Nunc demum a me insipienter factum esse arbitror / quom rem cognosco; at non malitiose tamem / feci. PE. Immo indigne; nam hominem seruom suos / domitos habere oportet oculos et manus / orationemque. Sc. Ego<ne〉 si post hunc diem / muttiuero, etiam quod egomet certo sciam, / dato excruciandum me: egomet me dedam tibi; / nunc hoc mi ignosce quaeso. Pe. Vincam animum meum, / ne malitiose factum id esse aps te arbitrer. / Ignoscam tibi istuc. Sc. At tibi di faciant bene! (Plaut., Mil. 561-570).

\section{Ofrecimiento de reparación}

La oferta de recompensa o reparación permite restablecer la situación, sin necesidad de que haya una declaración que explicite el error cometido, lo que, como se ha dicho, facilitaba a la élite aristocrática la recuperación del equilibrio sin perder su preeminencia jerárquica ${ }^{42}$. En la comedia, en consonancia con el argumento típico de estas obras, la propuesta más frecuente para reparar los errores de los jóvenes es la de matrimonio - véase también (46) - Como complemento a la presentación de las causas y el reconocimiento de la culpa — citados supra, (15)—, así finaliza la disculpa del joven Diniarco en Truculentus:

(26) [Di.] Verum te opsecro ut tuam gnatam des mi uxorem, Callicles (Plaut., Truc. 841).

Pero las recompensas pueden ser de variado tipo:

Esta solicitud de perdón de Lisidamo es interpretada por Fulkerson 2013, p. 127, como un elemento más de su degradación y su feminización (status-lowering).

${ }^{42}$ Recuérdese (1). Al no estar presente el destinatario de la disculpa, tampoco podemos considerar un acto realizativo el siguiente parlamento del viejo Demifón en Mercator, aunque ilustra bien tanto el ofrecimiento de una reparación, como la alusión al desconocimiento que se verá más abajo: De. Supplici sibi sumat quid uolt ipse ob hanc iniuriam, / modo pacem faciatis oro, ut ne mihi iratus siet. I Si hercle sciuissem siue adeo ioculo dixisset mihi / se illam amare, numquam facerem ut illam amanti abducerem. / Eutyche, ted oro, sodalis eius es, serua et subueni: / hunc senem para me clientem; memorem dices benefici. / Ly. Ora ut ignoscat delictis tuis atque adulescentiae (Plaut., Merc. 991-997). 
(27) Al. Opsecro te-Sel. Valeas. Al. ut sinas-Sel. Nil moror. Al. expurgare me. / Sel. 〈Oppressas〉. Al. Sine dicam-〈ME.〉 Sati’ sapit mihi tuis periiuriis. / 〈Al. uera. Me. Si ea sunt,〉 at nunc non potis est. Al. Supplicium uolo / polliceri. SEL. At mihi aps te accipere non lubet ... (Plaut., Cist. 453-456) ${ }^{43}$.

(28) Iv. Mane. Arbitratu tuo ius iurandum dabo / me meam pudicam esse uxorem arbitrarier. / Id ego si fallo, tum te, summe Iuppiter, / quaeso Amphitruoni ut semper iratus sies (Plaut., Amph. 931-934).

(29) CA. Omnium primum sodalem me esse scis gnato tuo. / Is adi[i]t me, nam illum prodire pudet in conspectum tuom / propterea quia fecit quae te scire scit. Nunc te opsecro, stultitiae adulescentiaeque eiius ignoscas: tuost; / scis solere illanc aetatem tali ludo ludere. / Quidquid fecit, nobiscum una fecit: nos deliquimus. / Faenus, sortem, sumptumque omnem, qui amica 〈empta〉 est, omnia / nos dabimus, nos conferemus, nostro sumptu, non tuo (Plaut., Most. 1153-1161) ${ }^{44}$.

\section{La explicación de las causas}

La explicitación de las circunstancias que motivaron la infracción, que pueden ser ajenas e incontrolables para quien comete la falta ${ }^{45}$, funciona como disculpa en determinadas circunstancias y, puesto que estas causas minimizan la responsabilidad del emisor en la ofensa, contribuyen a la salvaguarda de su propia imagen. Así se aprecia en el siguiente parlamento del esclavo embrollador Leónidas, quien finge ante un mercader no haberlo visto antes y permite obviar una disculpa explícita, al referirse únicamente a la reacción del interlocutor:

${ }^{43}$ Los intentos del joven Alcesimarco de ofrecer una reparación son precedidos por el uso de varios diminutivos intensivos (issula, v. 450; germana mea sororcula, v. 451; mea matercula, v. 452), muestras de cortesía positiva, y se ven frustrados ante el rechazo de Selenia y la proxeneta, su madre Melénide.

44 A pesar de tratarse en puridad de una intercesión, el uso del plural incluye al hablante en el acto comisivo que realiza.

45 Una causa deóntica externa puede ser una explicación válida y resultar exculpatoria; al respecto es ilustrativo el siguiente consejo: GE. Vi coactum te esse inuitum. PH. Lege, iudicio. Ge. Tenes? (Ter., Phorm. 214). Cf. ibíd. 235-236. La misma comedia nos proporciona un ejemplo adicional: Seruom hominem causam orare leges non sinunt / neque testimoni dictiost (292-293). 
(30) ... LE. Ehem ${ }^{46}$, optume. Quam dudum tu aduenisti? / Non hercle te prouideram (quaeso, ne uitio uortas), / ita iracundia opstitit oculis. ... (Plaut., Asin. 449-451).

En las comedias, por su propio desarrollo argumental, son acostumbradas las excusas fundadas en el amor $^{47}$, el vino — véase además (15) y (37) — y la juventud $^{48}$ :

(31) To. Amoris uitio, non meo, nunc tibi morologus fio (Plaut., Persa 49) ${ }^{49}$.

(32) Ag. Amans per amorem si quid feci[t], Milphio, / ignoscere id te mi aequom est. Mi. Hau uidi magis. / Et nunc ego amore pereo. Sine te uerberem, / item ut tu mihi fecisti, ob nullam noxiam: / postid locorum tu mihi amanti ignoscito (Plaut., Poen. 140-144).

Pero las explicaciones pueden resultar tan peregrinas como la que presenta Júpiter a Alcmena, para eludir las acusaciones de deshonestidad que su esposo, el verdadero Anfitrión, acaba de proferir contra ella (cf. Amph. 891896) y volver a granjearse sus favores:

(33) Iv. Si dixi, nihilo magis es neque ego esse arbitror, / et id huc reuorti uti me purgarem tibi. / Nam numquam quicquam meo animo fuit aegrius / quam postquam audiui ted esse iratam mihi. / «Qur dixisti?» inquies. Ego expediam tibi. / Non edepol quo te esse inpudicam crederem; / uerum periclitatus sum animum tuom / quid faceres et quo pacto id ferre induceres. / Equidem ioco illa dixeram dudum tibi, / ridiculi caussa. ... (Plaut., Amph. 908-917).

${ }^{46}$ Aunque fingida, la sorpresa expresada por la interjección ehem contribuye a la minimización de la responsabilidad (cf. Unceta Gómez 2012, pp. 374-376), del mismo modo que el hercle que sigue enfatiza el compromiso del hablante con la verdad de la proposición.

${ }^{47}$ También presente en: Vnum hoc scito, contumeliae / me non fecisse causa, sed amoris (Ter., Eun. 877-878). Sobre estos versos, cf. Kruschwitz y Cleary-Venables 2013, pp. 74-75.

${ }^{48}$ A pesar de no constituir actos realizativos, compárese además con: Per amorem si quid fecero, clementi 〈hic〉 animo ignoscet (Plaut., Mil. 1252) y nam hoc quidem ferundum aliquo modost: / persuasit nox amor uinum adulescentia: / humanumst. Vbi scit factum, ad matrem uirginis / uenit ipsus ultro lacrumans orans obsecrans / fidem dans, iurans se illam ducturum domum. / Ignotumst tacitumst creditumst (Ter., Ad. 469-474). Se trata de un recurso habitual ya en la comedia nueva (según señala Gutzwiller 2012, p. 61), cuya aceptabilidad es estrictamente cultural. Difícilmente podrían ser válidas estas explicaciones en otros contextos.

${ }^{49}$ Clara parodia del lenguaje de los adolescentes en una conversación entre esclavos. 
Más razonable - y habitual - es apelar al desconocimiento o la falta de intención ${ }^{50}$ como causa de la molestia ocasionada, lo que combina bien con el uso de la oración condicional:

(34) Quaeso ignoscas si quid stulte dixi atque inprudens tibi (Plaut., Men. 1073).

(35) Si id est peccatum, peccatum inprudentiast / poetae, non quo furtum facere studuerit. / Id ita esse uos iam iudicare poteritis (Ter., Eun. $27-29)^{51}$.

Del mismo modo, engañado por el esclavo Palestrión, el soldado Pirgopolinices expone su ignorancia sobre el hecho de que la mujer a la que cree que ha seducido, Acroteleucia - una cortesana en realidad-, estuviera casada. Y así se expresa en el escarnio final de Miles gloriosus en el que se le amenaza con un castigo enormemente ejemplarizante, la castración:

(36) Pe. Qur es ausus subigitare alienam uxorem, inpudens? / Py. Ita me di ament, ultro uentumst ad me. PE. Mentitur, feri. / Py. Mane dum narro. PE. Quid cessatis? Py. Non licet mi dicere? / PE. Dice. Py. Oratus sum ad eam ut irem. Pe. Qur ire ausu's? Em tibi! (Plaut., Mil. 1402-1405).

Py. Opsecro hercle te ut mea uerba audias priu' quam secat. / PE. Loquere. Py. Non de nihilo factumst: uiduam hercle esse censui ${ }^{52}$, / itaque ancilla, conciliatrix quae erat, dicebat mihi (ibíd. 1408-1410).

Un caso especial es (37), puesto que se trata de una intercesión en la que la desaparición del problema ocasionado parece suficiente para restablecer el equilibrio:

${ }^{50}$ Cf. además: So. Primum hoc te oro, nequid credas me aduorsum edictum tuom / facere esse ausam. ... Sy. Nescioquid peccati portat haec purgatio (Ter., Haut. 623-625). El comentario de Siro no deja lugar a dudas sobre la interpretación del parlamento de Sóstrata.

${ }^{51}$ Por lo general, los prólogos terencianos están animados por una intención exculpatoria. Véase al respecto Kruschwitz y Cleary-Venables 2013, pp. 82-85.

${ }^{52}$ Cf. conseruam esse credidi (Ter., Eun. 858). 
(37) De. Ego, Nausistrata, esse in hac re culpam meritum non nego; / sed ea qui sit ignoscenda. ... / DE. Nam neque neglegentia tua neque odio id fecit tuo. / Vinolentu' fere abhinc annos quindecim mulierculam / eam compressit unde haec natast; neque postilla umquam attigit. / Ea mortem obiit, e medio abiit qui fuit in re hac scrupulus. / Quam ob rem te oro, ut alia facta tua sunt, aequo animo hoc feras (Ter., Phorm. 1014$1020)^{53}$.

... [DE.] Verum iam, quando accusando fieri infectum non potest, / ignosce: orat confitetur purgat: quid uis amplius? (ibíd. 1034-1035).

Con todo, la explicitación de las causas no es incompatible con el reconocimiento de la responsabilidad:

(38) Sc. Meruisse equidem me maxumum fateor malum / et tuae fecisse me hospitae aio iniuriam; / sed meam esse erilem concubinam censui, / quoi me custodem erus addidit miles meus. / Nam ex uno puteo similior numquam potis / aqua aquai sumi quam haec est atque ista hospita. / Et me despexe ad te per impluuium tuom / fateor. ... (Plaut., Mil. 547-554).

O bien se puede apelar a la responsabilidad ajena (39), lo que, en caso de que un tercero la asuma, puede derivar en una intercesión, como en (40):

(39) Pe. Qur me igitur patrem uocabas? Ac. Tua istaec culpast, non mea. / Non patrem ego te nominem, ubi tu tuam me appelles filiam? / ... / Postremo haec mea culpa non est: quae didici dixi omnia; / Epidicus mihi fuit magister. ... (Plaut., Epid. 587-588; 591-592).

(40) Qur non uenisti, ut iusseram, in tostrinam? Li. Hic me moratust. / Le. Siquidem hercle nunc summum Iouem te dicas detinuisse / atque is precator adsiet, malam rem ecfugies numquam. / Tu, uerbero, imperium meum contempsisti? Li. Perii, hospes. / Me. Quaeso hercle noli, Saurea, mea caussa hunc uerberare. / ... / ME. Saurea, oro / mea caussa ut mittas. ... (Plaut. Asin. 413-417, 431-432).

E incluso ser la explicación aducida en una intercesión:

${ }^{53}$ Kruschwithz y Cleary-Venables 2013, pp. 72-73, interpretan este pasaje como muestra de lo que denominan differentiation, táctica que «derives its main persuasive power from the implication that, overall, the situation could be worse» (p. 72). 
(41) Pн. Si est, patrue, culpam ut Antipho in se admiserit, / ex qua re minu' rei foret aut famae temperans, / non causam dico quin quod meritu' sit ferat. / Sed siqui' forte malitia fretus sua / insidias nostrae fecit adulescentiae / ac uicit, nostra[n] culpa east an iudicum, / qui saepe propter inuidiam adimunt diuiti / aut propter misericordiam addunt pauperi? (Ter., Phorm. 270-277) $)^{54}$.

La negación de la culpa, por otra parte, puede ser intensificada a través de un juramento ${ }^{55}$ :

(42) [PA.] Neque mea culpa hoc discidium euenisse, id testor deos (Ter., Hec. 476).

(43) [So] Verum ita me di ament itaque optingant ex te quae exoptem mihi ut / numquam sciens commerui merito ut caperet odium illam mei (Ter., Hec. 579-580).

El nivel mínimo de afectación con respecto a la falta cometida es la negación de la existencia del agravio, lo que, en función de lo restrictiva que sea la definición de disculpa podría dejar fuera de ese acto de habla ejemplos como los siguientes:

(44) ... Ly. Ita me amabit Iuppiter, / uxor, ut ego illud numquam deixi. Do. Etiam negas? (Plaut., Merc. 762-763).

(45) Ly. Nescis negoti quid sit, uxor, opsecro. / Concepteis uerbeis iam iusiurandum dabo / me numquam quicquam cum illa ... (ibíd. 789-791).

\section{LA DISCULPA EN EL NIVEL CONVERSACIONAL}

A pesar de lo que pueda colegirse de la anterior presentación de los ejemplos, supeditada al objetivo de ilustrar los distintos mecanismos para la expresión de la disculpa, el desarrollo de esta intención comunicativa puede

${ }^{54}$ Poco después se apela a la inexperiencia de la juventud: Functus adulescentulist / officium liberali': postquam ad iudices / uentumst, non potuit cogitata proloqui; / ita eum tum timidum ibi obstupefecit pudor (Ter., Phorm. 281-284). Kruschwitz y Cleary-Venables 2013, pp. 60-62, analizan este ejemplo como exponente de la estrategia de evasión de la responsabilidad (shifting the blame).

${ }^{55}$ Cf. además Ter., Hec. 697. 
extenderse a lo largo de varios turnos conversacionales, lo que favorece el empleo acumulativo de diversos recursos expresivos. Por lo tanto, en el nivel interaccional, entendida como un macroacto de habla que suele responder a un reproche (aunque también cabe su manifestación espontánea), la disculpa puede complicarse indefinidamente, en función de las reacciones del interlocutor.

Un largo pasaje de Aulularia (733-756) resulta ilustrativo de esta complejidad, a pesar de que en él se produce el equívoco de que, mientras el joven Licónides confiesa haber violado a la hija del avaro viejo Euclión, este último cree que el joven se está inculpando del robo de la olla con dinero que ha encontrado:

\begin{tabular}{|c|c|}
\hline $\begin{array}{l}\text {... Ly. Quia istuc facinus quod tuom / sollicitat animum, } \\
\text { id ego feci et fateor. }\end{array}$ & $\begin{array}{l}\text { RECONOCIMIENTO DE LA } \\
\text { FALTA }\end{array}$ \\
\hline Evc. Quid ego ex te audio? / & $\begin{array}{l}\text { SOLICITUD INDIGNADA DE } \\
\text { CONFIRMACIÓN }\end{array}$ \\
\hline Ly. Id quod uerumst. & CONFIRMACIÓN \\
\hline $\begin{array}{l}\text { Evc. Quid ego 〈de te〉 demerui, adulescens, mali, / quam } \\
\text { ob rem ita faceres meque meosque perditum ires liberos? / }\end{array}$ & REPROCHE \\
\hline Ly. Deu' mihi impulsor fuit, is me ad illam inlexit. & $\begin{array}{l}\text { EXPLICACIÓN DE LA CAU- } \\
\text { SA (DIVINIDAD) }\end{array}$ \\
\hline Evc. Quo modo? / & REPROCHE \\
\hline $\begin{array}{l}\text { Ly. Fateor peccauise 〈me〉 et me culpam commeritum } \\
\text { scio; / id adeo te oratum aduenio ut animo aequo ignos- } \\
\text { cas mihi. / }\end{array}$ & $\begin{array}{l}\text { NUEVO RECONOCIMIENTO } \\
\text { DE LA FALTA Y OFERTA DE } \\
\text { COMPENSACIÓN, DISCUL- } \\
\text { PA EXPLÍCITA }\end{array}$ \\
\hline $\begin{array}{l}\text { Evc. Qur id ausu's facere ut id quod non tuom esset tan- } \\
\text { geres? / }\end{array}$ & REPROCHE \\
\hline $\begin{array}{l}\text { Ly. Quid uis fieri? Factum est illud: fieri infectum non } \\
\text { potest. / Deos credo uoluisse; nam ni uellent, non fieret, } \\
\text { scio. / }\end{array}$ & $\begin{array}{l}\text { RECONOCIMIENTO DE LA } \\
\text { FALTA E INSISTENCIA EN } \\
\text { LA EXPLICACIÓN DE LAS } \\
\text { CAUSAS (LA DIVINIDAD) }\end{array}$ \\
\hline $\begin{array}{l}\text { Evc. At ego deos credo uoluisse ut apud me te in neruo } \\
\text { enicem. / }\end{array}$ & AMENAZA \\
\hline Ly. Ne istuc dixis. & SÚPLICA \\
\hline Evc. Quid tibi ergo meam me inuito tactiost? / & REPROCHE \\
\hline
\end{tabular}




\begin{tabular}{|l|l|}
\hline Ly. Quia uini uitio atque amoris feci. & $\begin{array}{l}\text { EXPLICACIÓN DE LAS CAU- } \\
\text { SAS (VINO Y AMOR) }\end{array}$ \\
\hline $\begin{array}{l}\text { Evc. Homo audacissume, / cum istacin te oratione huc ad } \\
\text { me adire ausum, inpudens! / Nam si istuc ius est ut tu } \\
\text { istuc excusare possies, / luci claro deripiamus aurum ma- } \\
\text { tronis palam, / postid si prehensi simus, excusemus ebrios } \\
\text { / nos fecisse amoris caussa. Nimi' uilest uinum atque } \\
\text { amor, / si ebrio atque amanti inpune facere quod lubeat } \\
\text { licet. / }\end{array}$ & \begin{tabular}{l} 
LACIÓN DE LA VALIDEZ DE \\
\hline $\begin{array}{l}\text { Ly. Quin tibi ultro supplicatum uenio ob stultitiam } \\
\text { meam. / }\end{array}$
\end{tabular} \\
\hline $\begin{array}{l}\text { EvC. Non mi homines placent qui quando male fecerunt } \\
\text { purigant. / Tu illam scibas non tuam esse: non attactam } \\
\text { oportuit. / EXPLÍCITA Y }\end{array}$ \\
\hline $\begin{array}{l}\text { Ly. Ergo quia sum tangere ausus, hau causificor quin eam } \\
\text { / ego habeam potissumum. ... }\end{array}$ & PA REPROCHE DISCUL- \\
\hline
\end{tabular}

Euclión, desde luego, no está dispuesto a permitir que Licónides se quede con la olla, lo que permite aclarar el motivo de la disculpa, que, por fin, se plasma a través de una expresión realizativa (optestor... ut mi ignoscas), acompañada de la explicación de las causas (desconocimiento en expresión condicional, primero; el vino y la juventud, después), que sirven como complemento a una declaración de responsabilidad, además de a una oferta de contraprestación:

(46) [Ly.] Qui homo culpam admisit in se, nullust tam parui preti / quin pudeat, quin purget sese. Nunc te optestor, Euclio, / ut si quid ego erga te inprudens peccaui aut gnatam tuam, / ut mi ignoscas eamque uxorem mihi des, ut leges iubent. / Ego me iniuriam fecisse filiae fateor tuae / Cereris uigiliis per uinum atque impulsu adulescentiae (ibíd. 790-795).

\section{Conclusiones}

Como se ha podido comprobar, las distintas estrategias empleadas en el latín de las comedias para la solicitud del perdón no son excluyentes, sino que resultan combinadas con mucha frecuencia. Junto a la explicitación léxica de esta fuerza ilocutiva, las estrategias implícitas, que pueden aparecer so- 
las o asociadas a la primera, se organizan en torno a un continuum que nos va alejando paulatinamente de la vinculación con la responsabilidad de la ofensa. En su selección intervienen factores como el grado de violación y la importancia de la ofensa, pero también criterios sociolingüísticos como la distancia social de los interlocutores, o su jerarquía relativa (cf. Blum-Kulka y Olshtain 1984, p. 209), que puede estar agravada, en el caso de la comedia, por la amenaza de un castigo físico, especialmente para los esclavos ${ }^{56} \mathrm{o}$ los antagonistas, factores todos ellos que correlacionan con el grado de elaboración y el carácter intensivo de este acto de habla. De hecho, la disculpa constituye un mecanismo narrativo empleado para recobrar el orden subvertido en el desarrollo de la obra, facilitando su desenlace (cf. Fulkerson 2013, pp. 114, 121, n. 6).

En tanto que acto de habla deferente con el oyente, la disculpa pone en peligro la imagen positiva de quien la realiza, es decir, su deseo de reconocimiento social, pues debe admitir un error, pero también afecta a su imagen negativa, el deseo de desarrollo de la propia voluntad, puesto que obliga al emisor a colocarse en una posición de inferioridad frente a quien debe conceder el perdón, que es, de acuerdo con la mentalidad antigua, una gracia y no una obligación. De ahí que la clase dirigente sea reacia a su expresión. A pesar de que la comedia supone, en muchos aspectos, una inversión utópica de la moral aristocrática tradicional, por ejemplo en el hecho de que un varón pueda cometer una falta que han de perdonar un varón más joven o una mujer, es decir, sujetos jerárquicamente inferiores a él ${ }^{57}$, si analizamos globalmente los datos del corpus - cuyo detalle puede verse en el esquema recapitulatorio (Tabla 1)-, dejando de lado los ejemplos de intercesión, encontramos que la situación es la esperable en una sociedad con una estratificación social tan marcada.

${ }^{56}$ Véanse, por ejemplo, las amenazas del viejo Periplectómeno a Esceledro, esclavo del militar, en Plaut., Mil. 501-513.

${ }^{57}$ Lo cual, más allá de un mecanismo subversivo explotado cómicamente, supone, de acuerdo con Gutzwiller 2012, p. 75, un cambio cultural radical con respecto a la situación anterior. 


\begin{tabular}{|c|c|c|c|c|c|c|c|c|c|c|c|c|c|c|}
\hline \multirow{3}{*}{ 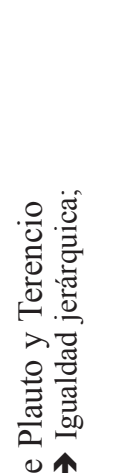 } & \multicolumn{2}{|c|}{ 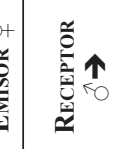 } & \multirow{2}{*}{ 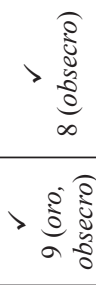 } & \multirow{2}{*}{ 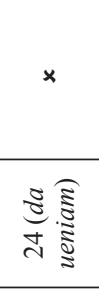 } & \multirow{2}{*}{\begin{tabular}{|l|}
$>\infty$ \\
$\underset{\sim}{\sim}$
\end{tabular}} & \multirow{2}{*}{\begin{tabular}{|c|}
$x$ \\
$\underset{T}{+}$ \\
\end{tabular}} & \multirow{2}{*}{$\begin{array}{c}x \\
>\infty \\
\infty\end{array}$} & \multirow{2}{*}{ 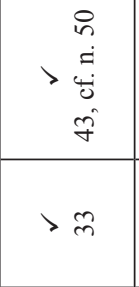 } & \multirow{2}{*}{$\begin{array}{l}x \\
x \\
x\end{array}$} & \multirow{2}{*}{$\frac{x}{>\stackrel{m}{d}}$} & \multirow{2}{*}{ 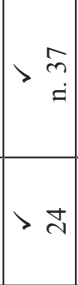 } & \multirow{2}{*}{$\begin{array}{l}>\infty \\
\times\end{array}$} & \multirow{2}{*}{\begin{tabular}{l|}
$>\infty$ \\
$\times$
\end{tabular}} & \multirow{2}{*}{$\begin{array}{r}>\mathscr{9} \\
\qquad \times\end{array}$} \\
\hline & $\left|\begin{array}{c}\text { o+ } \\
\text { of }\end{array}\right|$ & $\uparrow$ & & & & & & & & & & & & \\
\hline & 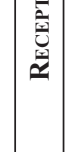 & $\rightarrow$ & $x$ & 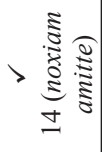 & $x$ & $x$ & $>\hat{\imath}$ & $x$ & $x$ & $x$ & $x$ & $x$ & $x$ & $x$ \\
\hline 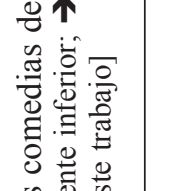 & \multirow[b]{3}{*}{ 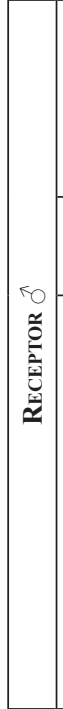 } & $\uparrow$ & $x$ & 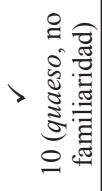 & $>0$ & & $>0$ & 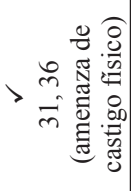 & $x$ & $x$ & $>\infty$ & $>0$ & $x$ & $>0$ \\
\hline 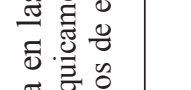 & & $\Rightarrow$ & $>\stackrel{\frac{0}{0}}{0}$ & $x$ & $x$ & $x$ & $>-$ & $>$ m & $x$ & $>\stackrel{m}{=}$ & $x$ & $x$ & $x$ & $x$ \\
\hline 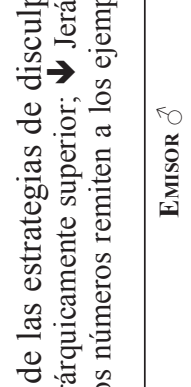 & & $\leftarrow$ & 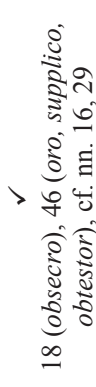 & 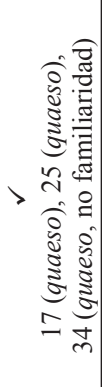 & 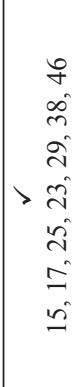 & $>a$ & 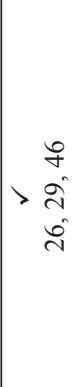 & 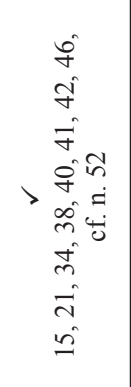 & 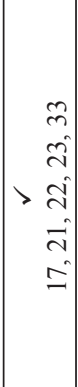 & 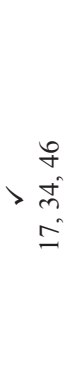 & 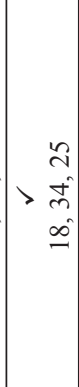 & $x$ & 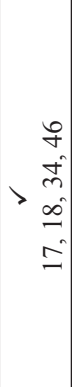 & 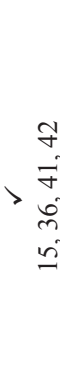 \\
\hline \multirow{2}{*}{ 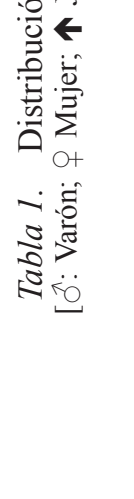 } & & & 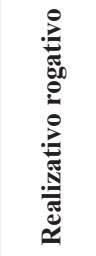 & 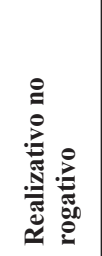 & 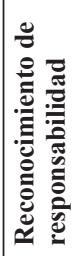 & 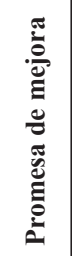 & 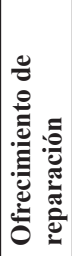 & 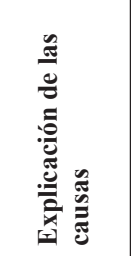 & 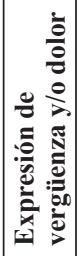 & 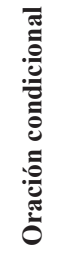 & 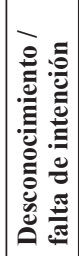 & 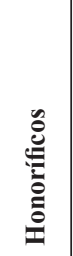 & 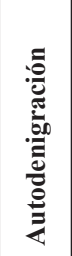 & 莺 \\
\hline & & & \multicolumn{2}{|c|}{ 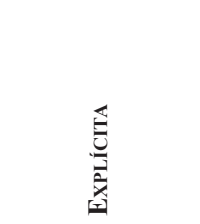 } & \multicolumn{5}{|c|}{ 氙 } & \multicolumn{2}{|c|}{ 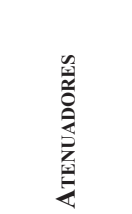 } & \multicolumn{3}{|c|}{ 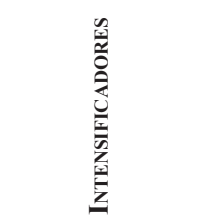 } \\
\hline
\end{tabular}


Así, y advertidos de que este no es un acto de habla muy representado en las comedias, a partir del análisis previo podemos extraer las siguientes conclusiones:

En primer lugar, no hay evidencias sólidas que permitan proponer diferencias de género, pues exceptuando un par de ejemplos anómalos, solo disponemos de la disculpa que presenta Sóstrata a su marido en Hecyra. Las mujeres de las comedias no cometen faltas por las que deban disculparse.

Con respecto a las disculpas dirigidas por un varón a una mujer, solo poco más representadas, nos situamos nuevamente en la intimidad de las relaciones amorosas y su carácter intensivo deriva directamente de la gravedad de la ofensa inferida.

Únicamente en la comunicación entre varones podemos constatar diferencias expresivas derivadas del criterio jerárquico:

- en consonancia con las tendencias anteriores, encontramos únicamente dos ejemplos en los que un superior se presta a disculparse de manera explícita y expresiva ante un inferior, ambos parlamentos dirigidos por un libre a un esclavo, gracias a cuya intervención el amo ha conseguido un beneficio

- igualmente escasas son las disculpas entre iguales; en este caso, el carácter intensivo puede estar motivado por la amenaza de un castigo físico

- de tal modo, donde encontramos el mayor número de intervenciones de disculpa es en las relaciones con sentido ascendente y, por lo general, dirigidas bien por esclavos a libres, bien por los adolescentes, debido a sus excesos, ya a los padres de sus amadas, ya a sus propios padres, casos estos en los que se acumulan las estrategias más expresivas y con mayor reconocimiento de responsabilidad.

Así pues, a pesar de las ventajas que ofrece el género cómico para el análisis de la cortesía lingüística, hemos de tener en cuenta que se trata de un corpus excesivamente homogéneo en muchos sentidos y que está muy condicionado por la estructura y la trama prototípicas de estas obras. En última instancia, si lo que se pretende es ofrecer un final feliz, no podría ser de otro modo. Todo ello complica, al menos en este caso, la obtención de resultados de tipo sociolingüístico y la generalización de tendencias expresivas ${ }^{58}$.

\footnotetext{
${ }^{58}$ Algo de lo que advierte Ferri 2008, p. 26; 2012, p. 125.
} 
Aun así, este análisis nos ha permitido reconocer un inventario amplio de mecanismos lingüísticos con los que un hablante latino podría expresar el acto de habla de la disculpa, en el que, al margen de la distancia social, los dos factores más relevantes - y responsables de su grado de elaboraciónson, según lo esperable, la gravedad de la ofensa y la relación jerárquica entre los interlocutores.

\section{BiBLIOGRAFÍA}

Afghari, A. 2007: «A Sociopragmatic Study of Apology Speech Act Realization Patterns in Persian», Speech Communication 49, pp. 177-185<http://www.sciencedirect.com/science/article/pii/S0167639307000076> (06/02/2014), doi: http:// dx.doi.org/10.1016/j.specom.2007.01.003.

Bataineh, R. F. y Bataineh, R. F. 2008: "A Cross-cultural Comparison of Apologies by Native Speakers of American English and Jordanian Arabic», Journal of Pragmatics 40, pp. 792-821 <http://www.sciencedirect.com/science/article/ pii/S0378216608000210> (06/02/2014), doi: http://dx.doi.org/10.1016/j.pragma.2008.01.003.

Blum-Kulka, S. y Olshtain, E. 1984: «Request and Apologies: A Cross-cultural Study of Speech Act Realization Patterns», Applied Linguistics 5, pp. 196-213<http:// applij.oxfordjournals.org/content/5/3/196.citation> (06/02/2014), doi: 10.1093/ applin/5.3.196.

Brookins, T. A. 2010: «A Politeness Analysis of Catullus' Polymetric Poems: Can Leech's GSP Cross the Ancient Modern Divide?», Journal of Pragmatics 42, pp. 1283-1295<http://www.sciencedirect.com/science/article/pii/S0378216609002458> (06/02/2014), doi: http://dx.doi.org/10.1016/j.pragma.2009.09.014.

Brown, P. y Levinson, S. C. 1987: Politeness. Some Universals in Language Usage, Cambridge.

Coulmas, F. 1981: «Poison to Your Soul. Thanks and Apologies Contrastively Viewed», en Coulmas, F. (ed.), Conversational Routine: Explorations in Standardized Communication Situations and Prepatterned Speech, La Haya - Nueva York, pp. 273-288.

Dickey, E. 2012: «The Rules of Politeness and Latin Request Formulae», en Probert, Ph. y Willi, A. (eds.), Laws and Rules in Indo-European, Oxford, pp. 313-328.

Edmonson, W. J. 1981: «On Saying You're Sorry», en Coulmas, F. (ed.), Conversational Routine: Explorations in Standardized Communication Situations and Prepatterned Speech, La Haya - Nueva York, pp. 273-288.

Ferri, R. 2008: «Politeness in Latin Comedy. Some Preliminary Thoughts», MD 61, pp. 15-28. 
Ferri, R. 2012: «How to Say No in Latin: Negative Turns, Politeness and Pragmatic Variation», en Leiwo, M., Halla-aho, H. y Vierros, M. (eds.), Variation and Change in Greek and Latin, Helsinki, pp. 105-127.

Fraser, B. 1981: «On Apologizing», en Coulmas, F. (ed.), Conversational Routine: Explorations in Standardized Communication Situations and Prepatterned Speech, La Haya - Nueva York, pp. 259-271.

Fulkerson, L. 2013: No Regrets. Remorse in Classical Antiquity, Oxford.

Griswold, Ch. L. y Konstan, D. (eds.) 2012: Ancient Forgiveness. Classical, Judaic, and Christian, Cambridge.

Gutzwiller, K. 2012: «All in the Family: Forgiveness and Reconciliation in New Comedy», en Griswold, Ch. L. y Konstan, D. (eds.), Ancient Forgiveness. Classical, Judaic, and Christian, Cambridge, pp. 48-75.

Hall, J. 2009: Politeness and Politics in Cicero's Letters, Oxford - Nueva York.

Hatfield, H. y Hahn, J.-W. 2011: «What Korean Apologies Require of Politeness Theory», Journal of Pragmatics 43, pp. 1303-1317 <http://www.sciencedirect. com/science/article/pii/S0378216610003620> (06/02/2014), doi: http://dx.doi. org/10.1016/j.pragma.2010.10.028.

Kampf, Z. 2009: «Public (Non-)Apologies: The Discourse of Minimizing Responsibility», Journal of Pragmatics 41, pp. 2257-2270 <http://www.sciencedirect. com/science/article/pii/S0378216608003007> (06/02/2014), doi: http://dx.doi. org/10.1016/j.pragma.2008.11.007.

Kasper, G. 1990: «Linguistic Politeness: Current Research Issues», Journal of Pragmatics 14, pp. 193-218, <http://www.sciencedirect.com/science/article/ pii/037821669090080W> (21/04/2014), doi: http://dx.doi.org/10.1016/03782166(90)90080-W.

Konstan, D. 2011: Before Forgiveness: The Origin of a Moral Idea, Cambridge.

Konstan, D. 2012: «Assuaging Rage: Remorse, Repentance, and Forgiveness in the Classical World», en Griswold, Ch. y Konstan, D. (eds.), Ancient Forgiveness. Classical, Judaic, and Christian, Cambridge, pp. 17-30.

Kruschwitz, P. y Cleary-Venables, A. 2013: «How to Apologise in Latin: A Case Study», en Moore, T. J. y Polleichtner, W. (eds.), Form und Bedeutung im lateinischen Drama / Form and Meaning in Latin Drama, Trier, pp. 53-86.

Lakoff, R. T. 2001: «Nine Ways of Looking at Apologies: The Necessity for Interdisciplinary Theory and Method in Discourse Analysis», en Schiffrin, D., Tannen, D. y Hamilton, H. (eds.), Handbook of Discourse Analysis, Londres, pp. 199-214.

Márquez Reiter, R. 2000: Linguistic Politeness in Britain and Uruguay. A Contrastive Study of Requests and Apologies, Amsterdam - Filadelfia.

Meier, A. J. 1998: «Apologies: What Do We Know?», International Journal of Applied Linguistics 8/2, pp. 215-231 <http://onlinelibrary.wiley.com/ 
doi/10.1111/j.1473-4192.1998.tb00130.x/abstract> (06/02/2014), doi: 10.1111/ j.1473-4192.1998.tb00130.x.

Molina Ávila, C. 2011: «Routes for Development in the Pragmaticalization of sorry as a Formulaic Marker», Revista Alicantina de Estudios Ingleses 24, pp. 191-212.

Morton Braund, S. 2012: «The Anger of Tyrants and the Forgiveness of Kings», en Griswold, Ch. L. y Konstan, D. (eds.), Ancient Forgiveness. Classical, Judaic, and Christian, Cambridge, pp. 79-96.

Moussy, C. 2011: «Champ lexical et polysémie: L'expression du pardon en latin», en La polysémie en latin, París, pp. 41-54 [=Calboli, G. (dir.), Papers on Grammar IX, 1. Latina Lingua, Roma, 2005, pp. 359-370.]

Newbold, R. 2001a: «Pardon and Revenge in Suetonius and the Historia Augusta», Prudentia 33, pp. 40-47.

Newbold, R. 2001b: «Pardon and Revenge in Tacitus and Ammianus», Electronic Antiquity 6/1, <http://scholar.lib.vt.edu/ejournals/ElAnt/V6N1/newbold.html> (12/05/2013).

Norrick, N. R. 1978: «Expressive Illocutionary Acts», Journal of Pragmatics 2, pp. 277-291 <http:/www.sciencedirect.com/science/article/pii/037821667890005X> (06/02/2014), doi: http://dx.doi.org/10.1016/0378-2166(78)90005-X.

Obeng, S. G. 1999: «Apologies in Akan Discourse», Journal of Pragmatics 31, pp. 709-734 <http://www.sciencedirect.com/science/article/pii/S0378216698000897> (06/02/2014), doi: http://dx.doi.org/10.1016/S0378-2166(98)00089-7.

Ogiermann, E. 2009: On Apologising in Negative and Positive Politeness Cultures, Amsterdam - Filadelfia.

Olshtain, E. y Cohen, A. 1983: «Apology: A Speech Act Set», en Wolfson, N. y Judd, E. (eds.), Sociolinguistics and Language Acquisition, Rowley (MA), pp. 18-35.

Olshtain, E. 1989: «Apologies Across Languages», en Blum Kulka, S., House, J. y Kasper, G. (eds.), Cross Cultural Pragmatics: Requests and Apologies, Norwood (NJ), pp. 155-173.

Roesch, S. 2004 «La politesse dans la correspondance de Cicéron», en Nadjo, L. y Gavoille, E. (eds.), Epistulae Antiquae III, Lovaina, pp. 139-152.

Rosivach, V. J. 1972: «Terence, Adelphi 165-6», The Classical Review 22/1, pp. 8-9 $<$ http://journals.cambridge.org/abstract_S0009840X00231685> (06/02/2014), doi: 10.1017/S0009840X00231685.

Sánchez Jiménez, S. U. 2006: «Intercambios comunicativos en el español clásico (tras los Pasos de Lope de Rueda)», Romanistisches Jahrbuch 57, pp. 352-377.

Scodel, R. 2008: Epic Facework: Self-presentation and Social Interaction in Homer, Swansea.

Searle, J. 1976: «Una taxonomía de los actos ilocucionarios», Teorema 6(1), pp. 43-77.

Siebold, K. 2007: «La cortesía verbal: Estudio contrastivo de la disculpa en español y en alemán», Oralia. Análisis del discurso oral 10 (Anejo 3/2), pp. 759-769. 
Schrijvers, P. H. 1993: «Amicus liber et dulcis. Horace moraliste», en Ludwig, W. (ed.), Horace. L'œuvre et les imitations. Un siècle d'interprétation, Ginebra, pp. 41-94.

Taffeteller, A. 2003: «Homeric Excuses», CQ 53/1, pp. 15-31<http://www.jstor.org/di scover/10.2307/3556479? uid $=3737952 \&$ uid $=2 \&$ uid $=4 \&$ sid $=21103467287523>$ (06/02/2014), URL permanente: <http://www.jstor.org/stable/3556479>.

Unceta Gómez, L. 2009: La petición verbal en latín. Estudio léxico, semántico y pragmático, Madrid.

Unceta Gómez, L. 2010: «La expresión del agradecimiento en la comedia latina», en Anreiter, P. y Kienpointner, M. (eds.), Latin Linguistics Today. Akten des 15. internationalen Kolloquiums zur lateinischen Linguistik, Innsbruck, pp. 625-637.

Unceta Gómez, L. 2012: «Cuando los sentimientos irrumpen. Valores expresivos de las interjecciones primarias en las comedias de Plauto», en López Gregoris, R. (ed.), Estudios sobre teatro romano: el mundo de los sentimientos y su expresión, Zaragoza, pp. 347-395.

Unceta Gómez, L. 2014: «La politesse linguistique en latin. Bilan d'une recherche en cours», Dictionnaire Historique et Encyclopedie Linguistique du Latin (DHELL), Partie encyclopédie linguistique $<$ http://www.linglat.paris-sorbonne.fr/>.

Watts, R. J. 2003: Politeness, Cambridge. 